\title{
The Pedagogical Question as Quest in Learning
}

\author{
Arturo G. Rillo ${ }^{1}$, Beatriz E. Martínez-Carrillo ${ }^{2}$, Javier Jaimes García ${ }^{3}$, \\ Héctor L. Ocaña Servín ${ }^{3}$ \\ ${ }^{1}$ (Academic Area of Philosophy, Faculty of Medicine / Autonomous University of the State of Mexico, Mexico) \\ ${ }^{2}$ (Nutrition Research Laboratory, Faculty of Medicine / Autonomous University of the State of Mexico, Mexico) \\ ${ }^{3}$ (Department of Pharmacology, Faculty of Medicine / Autonomous University of the State of Mexico, Mexico)
}

\begin{abstract}
When the pedagogical discourse is analyzed from the philosophical hermeneutics, the dialectic of question and answer acquires diverse senses related to the mode of learning. For this reason, the study was carried out with the purpose of analyzing the meaning, structure and fusion of horizons of the pedagogical question as a quest process during the student's learning. Initially, a horizon of understanding was constructed through the coordinates proposed by Heidegger (point of view, direction of the gaze and horizon of sight), and the constructivist educational tradition. The pedagogical question as an expression of a quest reveals learning by appearance while asking about what we know in advance. On the other hand, the question anticipates the response, gives meaning to the receptive learning guided by imitation and, finally, when the answer to the question is accessible to the understanding, the student is situated in front of the learning by unconcealment and appropriation of the true knowledge. It is concluded that the construction of learning through the question as a quest, is linked to hermeneutical pre-comprehension as it reveals the situation of the student in the world of life.
\end{abstract}

Keywords: learning, philosophical hermeneutics, pedagogical question, questioning skills

\section{Introduction}

Education is a process of formation by which the tradition in which the student lives is appropriated and rehabilitated. In this sense Gadamer points out that education is self-education [1], concretizing in this expression the educational tendencies that place the learning process of the student, in the center of the world that surrounds him [2]. In education oriented toward understanding the world, the construction of reality is elaborated from the relations established by the subject with the objects that surround him and participate in his world $[3,4]$.

This dynamic makes education a process that transcends the appropriation of the world and provides meaning to the transformation of reality. In aspiring to a better world, the student appropriates the cognitive, procedural and attitudinal tools to penetrate the paths of life in search of their realization as a human being [5].

Consequently, learning is not thought of as an isolated process, outside the context in which the learner develops. Looking at himself there, he understands his participation in the process of building the reality in which he lives and in the rehabilitation of the tradition to which he belongs [6]. In this self-apprehension, the learner appropriates language to express the world and develop its capacity for wonder [7], facilitating the inquisitive attitude with which the human being approaches to understand his environment from a linguistic and symbolic context. In this sense, education is configured as understanding and links the capacity for wonder with the need to adapt to the natural and social environment [8].

During the transformation that the human being makes of his environment, the meaning is determined in which he will travel through the world of life; so that, as it grows and develops biologically, it faces a book that must interpret, understand and apply what has been learned. In the book that is shown to the life of the subject, the relations with useful objects that are exposed to human existence happen to configure the material conditions of life. In addition, the sense that will give each relationship in the complexity of their life is determined by the quest that realizes. This quest is configured through coexistence with oneself, with one you or with others. In all these experiences, a process of learning of dialogic characteristics underlies, but when the teacher's knowledge meets the learning needs of the student, an encounter is established, of a pedagogical nature, in which a discourse is expressed that needs to be interpreted, understood and applied.

Given the hermeneutic, pedagogical and dialogic nature of pedagogical discourse, the knowledge acquired during the pedagogical encounter requires the interconnection between the hermeneutic circle [9] and the pedagogical discourse, which is carried out through the logic of the question.

The question in the classroom has been used by the teacher as a tool to explore the knowledge of a topic, to attract the attention of the student, to promote the construction of knowledge, to promote the development of critical thinking and creative thinking; which is recommended as a teaching and learning strategy, both in educational approaches based on behaviorism and educational technology as in constructivism 
[11-14]. In the teacher as manager of knowledge, the question as a methodological tool in the educational field is a pedagogical question [15].

In this sense, the pedagogical question is shown as a strategy that stimulates mental activity, favors the development of the mental structures of the human being and the construction of knowledge stimulates the capacity to think and the creation of convergent or divergent thoughts. It also enables processes of reflection, autonomy and self-questioning to contribute to decision-making, conflict resolution and face life as best as possible $[13,15,16]$.

The pedagogical use of the question opens up ways of reflection and understanding of what is being known, giving content to the experience of the vital praxis of the human being; so that the pedagogical question can guide learning as a process of quest for truth, or as the path that is being built to gradually approach reality, as well as expressing itself from human existence $[15,17]$. When the pedagogical question is shown as quest, it makes it possible to mobilize cognitive structures to promote critical, reflexive and creative learning. In this context, the following question arises: what possibilities open the hermeneutics in the understanding of the pedagogical question as quest?

The question as a didactic tool recovers the background on which learning is built to increase the development and satisfaction of the student's learning needs. From philosophical hermeneutics, the pedagogical question opens a horizon that rehabilitates the hermeneutic process of pre-comprehension in the dynamics of learning construction. In this sense, the study was carried out with the purpose of analyzing the meaning, structure and fusion of horizons of the pedagogical question as a quest process during student learning.

\section{Starting Point}

The study is confined to philosophical research from the field of philosophical hermeneutics developed by Hans-Georg Gadamer [18]. This approach allowed us to locate the pedagogical question as a hermeneutic problem, to open the possibility of understanding the experience of being-in-the-world from the tradition in which the subject lives, and to understand the mobility of meaning from the historicity of the underlying man in the effective-historical consciousness.

Exploring the possibilities opened by philosophical hermeneutics in the understanding of the pedagogical question as quest requires setting a horizon of understanding; that is, a starting point. This will allow us to project the analysis towards the construction of the meaning of the pedagogical question as quest; so that by exploring the meaning, structure and fusion of horizons, it is possible to understand the pedagogical question as openness to the quest for knowledge and learning as an art of thinking. For this reason, the starting point was constructed by the following coordinates: point of view, direction of the gaze and horizon of the sight.

\subsection{Point of view}

The point of sight is the horizon of meaning given previously [19]; that is, the prejudices that underlie the tradition in which the subject is immersed. It allows to cut, to focus and to direct the previous way in which it is presented to our understanding the teaching task to try to reconstruct, originally and interrogatively, the horizon for the understanding of the pedagogical question.

The cut that is realized during the reconstruction of the point of sight implies the relation that is established between the prejudices and the pre-comprehension of the sense when becoming aware of the influence that the tradition exerts to being-in-the-world [18]. From the constructivist educational tradition, pedagogical and didactic work was cut out to identify the way in which the use of the question is presented as quest and its relationship with the construction of learning.

In the point of view, prejudices become relevant because they are shown to the subject as the previous way of seeing and understanding of which part to found the interpretation [20]. On the other hand, preunderstanding constitutes the background where the immediate understanding of the context moves. In the context, the problem of the social construction of reality is shown through the elaboration of the knowledge and the way of learning of the subject. Understanding the role of pre-understanding in the constructive dynamics of reality is made possible by the pedagogical question; since its use integrates two fundamental elements: the sense of prejudices determined by historical-effectual consciousness and the dynamics of the hermeneutic circle.

\subsection{Direction of the gaze}

Analyzing the pedagogical question as a hermeneutical task involves reflecting the problem of the construction of knowledge and learning. This was initially taken care of when developing the point of view. It continues with the direction of the gaze, which complements the hermeneutic process because it leads to the perspective under which the pedagogical question. Considering the impossibility of achieving an absolute and complete knowledge, the pedagogical question was placed in perspective from the existence to think it from and within the factual life.

Heidegger indicates that the direction of the gaze includes the "as-something" and the "towards-where" [19]. In pointing out the pedagogical question "as-something", the subject's pre-understanding is determined by looking 
at it as an object of interpretation; the "towards-where" specification guides and indicates the direction in which the pedagogical question should be interpreted.

The "as-something" defines pre-comprehension in its connection with historical-effectual consciousness and recovers the previous way of seeing the pedagogical question as quest to formalize it with the existential integration of the hermeneutic circle $[19,21]$.

The "towards-where" implies the existential and experiential sense in which the perspective under which is placed the use of the pedagogical question, considering the context of the social construction of the learning that the student performs, for which it is necessary to submit it to the circumspection of the historical-effective consciousness that underlies the educational tradition [19,21].

In this context, the prejudices and the pre-comprehension of the pedagogical question as quest during the educational process are configured in the instrument that facilitates the construction of learning; for this reason, it must be constantly subjected to the circumspection of the Western educational tradition. The systematic analysis from the tradition makes it possible to recover the historical-effective consciousness that underlies the pedagogical practice of the question in the different learning scenarios.

The pedagogical practice is shown as a concretion of the articulation of the interpretation, understanding and application of the hermeneutic process in the appropriation of reality through the hermeneutic circle. It will then be the hermeneutic circle that makes it possible to link the pedagogical question with the context of tradition through the historical-effectual consciousness. This implies that it is in the pedagogical praxis where it becomes evident that the pedagogical question is not limited to determining how the learning can be understood from the constructivist tradition, but how the meaning of the pedagogical question is constructed. The pre-understanding that derives from the direction of the gaze, allowed included existential and experiential referents of learning as a compulsory subject to understand the pedagogical question as well as the possibility of formalizing it.

Access to the problem of the pedagogical question was made from the inter-human phenomenon in its full concretion in the factual life. The relation with the positivist approach to pedagogy, dominated by the scientific model of the natural sciences, was avoided. On the other hand, specific situations were recovered in which the man feels called and interrogated, that renew the tradition and motivate to ask for the factum of the life from a humanistic approach.

\subsection{Horizon of the gaze}

The point of view and the direction of the gaze delimit the horizon of the gaze. In the hermeneutic task, the horizon establishes a space in which the objectivity of the hermeneutical analysis is played, placing in it the pretension of objectivity of all interpretation [19]. The game between objectivity and subjectivity of the interpretation of symbolic contents of reality, is generated through the conceptual repertoire that the subject available to expand understanding; that is, pre-understanding, guide and enables the recovery and rehabilitation of historical-effective consciousness through the fusion of horizons [19].

The horizon of the gaze centers the problem of the objectivity of the hermeneutical analysis of the pedagogical question. Objectivity in the interpretation of the pedagogical question is limited to the understanding of the previous relation established between the human being (cognoscent subject) and reality (object of knowledge) in which the understanding of the question is delineated answer back. This implies that the objectivity of learning is not the essential point to understand and pose the pedagogical questions, but the participation of the human being who presents himself in the construction of knowledge by himself and in a collaborative way. The problem of objectivity in the hermeneutic interpretation of the pedagogical question is practical rather than theoretical.

\section{Sense Of The Pedagogical Question As Quest}

Previous studies have shown that the pedagogical question opens the possibility of uncovering the truth of being and establishing dialogue with tradition, corresponding to two paths of hermeneutic comprehension: the hermeneutics of facticity and philosophical hermeneutics [15,17,22]. In both cases, it was found that the question presents three meanings indicated by Heidegger for his understanding: as a quest [23], as a way that is constructed [24] and as an act of human existence [20].

If the pedagogical question is understood as the original act of search that the human being realizes in being-in-the-world, what possibilities of dialogue does it offer to the tradition of social constructivism? Exploring this question as quest has the following characteristics: represents the investigative activity, the precomprehension guides the anticipation of the response.

For Heidegger, the question as a quest acquires the sense of inquiry, so that to investigate is to quest. The search implies the anticipation of the answer, because only what we know is-there is sought; so that the inquisitive attitude is shown through the question that elaborates from the pre-understanding [23]. When beingin-the-world asks what he knows in advance, he exposes the determination of social and cultural factors to make the question accessible to understanding. 
The pedagogical question, then, guides our walk in the path of thinking, the accessibility to the answer that is sought and is hidden to our understanding, the construction of the path to uncover the truth and anticipate the historical and finite project that is the being human. That is, the task of asking involves looking at what is asked, understood, conceptualized, chosen, to access the question [20].

When interrogating the educational tradition for the pedagogical question as a search, one is asking for something so obvious that it slips into daily conversation and obscures the origin of the question; hence the importance of the preliminary understanding of the pedagogical question. In this sense, for Gadamer to understand a question means to ask [18]. To ask it involves reconstructing the question from the tradition that is speaking and listening. In this dialogue, the pedagogical question is said; in a saying that anticipates a statement that shows: where the gaze directed, the understanding and the conceptualization of the starting point was directed; in addition to exposing the basis of the question to show the knowledge that is constructed by understanding the question.

The statement that answers the pedagogical question shows the knowledge that is latent in the interaction of social and cultural factors that the subject performs in collaborative praxis. The answer is expressed so as to make evident what is gathered and what is separate; that is, it exposes the possibility of meaning that has been opened through the question. The meaning in the understanding is not restricted to the meaning of content; rather, it refers to the "existential phenomenon already characterized in which the formal structure of what can be open in understanding and articulated in interpretation becomes visible" [20]. From this arises the following question: how does the acquisition of meaning to a question become possible?

It will be through the nature of motivation that it gives meaning to the question [25]; however, it is not possible to find the full meaning of each question, since the mobility of meaning comes into play in the context of historical-effectual consciousness. The nature of motivation offers the possibility of elaborating pedagogical questions that attend different levels of concretion to understand the reality of the world of life.

The hermeneutical analysis of the pedagogical question opens the possibility of putting the facts of the factual life in the following levels: memory, comprehension, interpretation, application, analysis, synthesis and evaluation. By moving through these levels through the application of the hermeneutic circle (interpretunderstand-apply) it is possible to establish the correlation between the features of the meaning of the question with the mode of being interrogative and the mode of apprehending. This correlation is presented in Table 1.

Table 1. Correlation between the features of the meaning of the pedagogical question, the mode of being interrogative and the mode to learn.

\begin{tabular}{|l|l|l|}
\hline Features & Mode of being interrogative & Mode to learn \\
\hline Investigative activity & Inquisitive attitude & Discovery learning [26] \\
\hline Anticipation of the response & Pre- understanding & Cooperative learning [27] \\
\hline
\end{tabular}

\section{Structure Of The Pedagogical Question As Quest}

To pose the pedagogical question requires specifying the structure of the question, what to say of Heidegger includes: the question in question, it asked and the interrogated [20].

\subsection{The question in question}

The question in question, it refers in the question that we have to elaborate; so that one speaks of the question itself; that is, the question should be asked. What to question the pedagogical question? The possibility of constructing knowledge and learning that is shown-in-itself as a particular mode of being, which is essentially distinguished from learning by discovery [26] and as appearance [28].

In the quest carried out through the pedagogical question, the question that is addressed to the question itself arises from the anticipation offered by the experience of the previous experiences that the student has internalized. In this inherent pre-comprehension of human existence lie the answers to which the student resorts when he is asked questions that explore the content of his memory [29].

Asking the world of life from the previous knowledge that the student possesses leads him, on the one hand, to an inquisitive attitude compatible with appearance learning [28] because he asks about what is shownin-itself; and on the other, it rehabilitates the preliminary understanding that derives from the fact of belonging to a tradition and sets it as the backdrop on which the mobility of the pedagogical question is shown. It is through this mobility that the horizon is opened from which the answer obtained in the question-answer logic will be understood and from which it transits through different horizons $[14,30]$.

1.5. It asked

The question expresses the meaning of what is asked. Involves the motivation in the construction of the question so it requires the elaboration of own concepts. What is questioned then is the sense of knowledge and learning in themselves, because we call learning many things and in many meanings. When the sense of knowledge is in terms of search, the response is anticipated and conducive to receptive learning guided by imitation [31]. It is through imitation as tradition manifests itself in the pedagogical process linked to the use of 
the question. Here, the pedagogical question acquires the sense that the effective history determines so that the subject is understood in the world.

\subsection{The interrogated}

The questioned is what is questioned as a possibility to understand reality. This implies that it is the question that is elaborated what constitutes the question in question. Understanding the question as a pedagogical fact suggests that what is questioned in the pedagogical question is reality itself. By asking, reality is shown-in-itself in its most original sense, in a way that allows it to be uncovered and to keep open the possibility of its comprehension.

To find the answer you are looking for, you must be accessible to understanding and have the possibility to be shown in your true self. In the dialectic of question and answer, a dialogue is drawn that liberates the tradition of the circumspective occupation of being-in-the-world. Everyday life hides the possibility of understanding reality; reason why, the question allows the student to learn by "unconcealment" the truth [32]. When the question that was hidden is found, accessibility to the answer leads to the question itself; so that the anticipated response shows the true meaning of learning.

\section{Fusion Of Horizons}

The fusion of horizons is the product of the rehabilitation of historical-effective consciousness and the conceptual repertoire available in pre-comprehension to expand understanding [21]. The conjunction of both elements offers the possibility of objectivity possesses all interpretation [19]. The objectivity that underlies the horizon is not reduced to the simple fusion of different ways of seeing reality, but to the understanding of the previous relationship established between the human being and the world of life. This relationship characterizes the being-in-the-world during the process of symbolic and social construction of reality; construction based on the understanding of what is sought through the question.

In this context, the objectivity of the question lies in the breadth of the horizon of understanding in articulating the previous conception of the world (prejudices), the previous way of seeing (pre-comprehension) and the previous way of understanding (historical-effectual consciousness) [20].

To ask objectively implies the project of the tradition to which the individual belongs and from which the object subject to understanding is shown to the understanding. Thus, the objectivity of the question lies in the dialogue where the dialectic of the hermeneutic circle operates.

The possibilities of understanding are infinite, depending on the number of speakers who establish the dialogue with tradition. Hence the fusion of horizons offers the possibility of establishing criteria of truth for the understanding of the relationships established by the subject with the world of life. Following this line of reflection, it is identified that the fusion of horizons is made possible by the linking of three scales: horizon from which tradition interrogates, horizon from which the tradition is interrogated and horizon arising from the historical-effectual consciousness.

In the process of learning, the teacher acquires the responsibility of establishing a dialogue with tradition. In order to delineate the fusion of horizons in the context of the pedagogical tradition of constructivism, Table 2 shows the link between the structure of the pedagogical question and the fusion of horizons, and it is possible to unconcealment different levels of concretion of learning that are explained below.

Table 2. Matrix showing the link between: structure and fusion of horizons of the pedagogical question as quest, during the pedagogical encounter.

\begin{tabular}{|l|l|l|l|}
\hline Structure & Fusion of horizons \\
\cline { 2 - 4 } & $\begin{array}{l}\text { Horizon from which } \\
\text { tradition interrogates }\end{array}$ & $\begin{array}{l}\text { Horizon from which the Horizon arising from the } \\
\text { tradition is interrogated }\end{array}$ & $\begin{array}{l}\text { fistorical-effectual } \\
\text { consciousness }\end{array}$ \\
\hline $\begin{array}{l}\text { The question in question } \\
\text { (Ask the question) }\end{array}$ & Memory-mediated learning & $\begin{array}{l}\text { Learning oriented by } \\
\text { prejudices }\end{array}$ & Learning by appearance [28] \\
\hline $\begin{array}{l}\text { It asked } \\
\text { (Sense of what you ask) }\end{array}$ & $\begin{array}{l}\text { Receptive learning that is } \\
\text { confronted with the } \\
\text { previous experience of the } \\
\text { subject leceptive } \\
\text { incorporating the opinion of } \\
\text { the other }\end{array}$ & $\begin{array}{l}\text { Receptive learning guided by } \\
\text { imitation [31] }\end{array}$ \\
\hline $\begin{array}{l}\text { The interrogated } \\
\text { (Possibility of } \\
\text { understanding reality) }\end{array}$ & $\begin{array}{l}\text { Active learning in which } \\
\text { one aspires to understand } \\
\text { relationships with others }\end{array}$ & $\begin{array}{l}\text { Active learning guided by the } \\
\text { interpretation of its place in } \\
\text { the world. }\end{array}$ & $\begin{array}{l}\text { Active learning mediated by the } \\
\text { uncovering of truth [32] }\end{array}$ \\
\hline
\end{tabular}

\subsection{Tradition interrogates}

To say that the tradition interrogates refers to the question that the text asks the interpreter; That is, the teacher, who asks, is interrogated by tradition. Here in lies the consciousness of historical determination. The horizon from which tradition interrogates makes it possible to elaborate a preliminary question. It emerges from tradition through historical-effectual awareness and is a prerequisite for the elaboration of the pedagogical question that is shown in memory-mediated learning [33]. The knowledge that is generated in this type of

DOI: $10.9790 / 7388-0702032229 \quad$ www.iosrjournals.org $26 \mid$ Page


learning is a knowledge that comes from the experiences that accumulate without ceasing and awaken the question for the sense of things [34]. In this respect, Gadamer indicates that in a way, we already know through experiences, and yet we would want to know what is what gives them meaning [18]. Thus, memory is a form of quest that aspires to make present that which remains hidden in thought.

The meaning in the understanding of the pedagogical question as a quest is given through the dialogue that establishes the historical mediation of the present with the tradition. In this dialogue, receptive learning is enabled through confrontation with the student's previous experience.

The possibility of understanding reality is configured when being-in-the-world approaches vital situations, with the pretension of reconstructing the reality of factual life circumscribed to the world of life. From this horizon, the student initiates an active learning through which he aspires to understand the relations with the other, for which it deconstructs the tradition. The deconstruction of tradition takes place insofar as being-there conceals itself. The deconstruction, then, allows gradually reconstructing the understanding of the world of life by suspending the need for an appropriation of oneself.

\subsection{The tradition is interrogated}

From the point of view, the subject reflects in relation to the experiences that have given him the experiences produced in his being-in-the-world. Reflection that is delimited by: the previous knowledge contained in the pre-understanding of the world and that give meaning to the dialogue with socio-historically determined educational traditions. In this dialogue, the teacher begins the interrogation of tradition by asking for the processes of social construction of reality and its relation to learning. It asks questions such as: how to facilitate the student's learning in certain pedagogical scenarios?

Then the horizon from which the tradition is questioned, allows to reconstruct the pedagogical question from the tradition of which interrogates and to concretise the learning guided by the prejudices. When one moves towards learning by imitation, the logic of question and answer allows the student, in his quest for knowledge, to reconstruct the pedagogical question from the dialogical praxis of being-in-the-world. In this search for meaning, receptive learning incorporates the opinion of the other as he understands it from his own understanding.

The motivation of the question is oriented to the understanding of the world of life and its transformation. It is also directed to a structured project of human being that has aspirations of freedom. It is freedom as a life project, which structures and links the relationships that will remain in the subject. By rehabilitating the tradition to which he belongs and giving meaning to his life, the student travels in an area of freedom; which is why active learning is guided by the student's interpretation [36]. The central themes of the interpretation of the pedagogical question as a quest are: its place in the world, the reflective appropriation of tradition, and the object that is shown to the process of knowledge.

\subsection{Historical-effectual consciousness}

The dialogue with tradition, based on the logic of question-answer, is aimed at reconstructing the original question. Understanding the events of the student's life will be the expected response. In this dialectical relationship, a link is established between the existence that is lived and the memory of the events that happened before. Each one configures a horizon, from which a question can originally arise, but when it merges, it is revealed as the understanding of the original meaning of the pedagogical question. At this moment, there is the awareness of the influence that has produced the tradition in which we live.

In the horizon that emerges from the consciousness of the effective history the consciousness of the historical determination of the human being is rehabilitated; So that learning by appearance represents a preschematization of the possible experience and its first acquisition that are concretized in the particular situation of the student.

Through the horizon that emerges from the historical-effective consciousness, the dialectic of question and answer is rehabilitated from the relationship established with the other, which allows for mutual understanding and articulation of the world in common. This gives meaning to receptive learning guided by imitation, where the cognitive sense of what is represented by imitation is preserved. Then he who imitates something allows him to appear what he knows, as he knows it.

The horizon that emerges from the historical-effective consciousness, centers the understanding in the original sense of the transformative praxis, generated by the answer to the pedagogical question. This response is a product of active learning mediated by the unconcealment of truth; which it involves grounding the sense of understanding, hence its praxis in the transformation during the construction of learning.

\section{Conclusion}

The education of the human being, in its different dimensions, requires a deep reflection in terms of the sense that educate has in the XXI century. Faced with the skills required for being-in-the-world, pedagogy and didactics are reorienting their ways to rehabilitate the inquisitive nature and promote the capacity for wonder. Its ultimate purpose: to form a reflective and critical citizen. 
The pedagogical question has the possibility of promoting the development of reflexive and critical thinking. But approaching to understand the pedagogical question from its meaning and structure requires establishing a dialogue with the Western educational tradition. It will be through dialogue with tradition, the way in which the fusion of horizons is achieved, the historical-effective consciousness is shown and the constructivist pedagogical tradition is renewed.

The hermeneutical analysis performed in the study shows that the pedagogical question as a quest is based on factual life. Then, the learning during the life is an event that is concreteness in the measure in which the subject is exposed to the solution of different problems. The right solution will be in the function of the quality of the question that is generated, which requires articulating different theoretical and practical approaches related to learning. The above is achieved through recovering the human qualities of wonder and search for truth.

The pedagogical question as a search is an instrument that allows to explore the human existence when the student is-in-the-world. Existential relationships built in the world of life are apprehended by the student through the interpretation he performs from the experience of asking. Experience, that contributes to renew the processes of construction of learning, aiming to understand the reality. In addition, the experience of the questioning strengthens the analysis of the symbolic and social relations that give the student the sense to interact with his reality.

The construction of the knowledge that the student makes through the pedagogical question as a quest, is realized through the integration of previous knowledge, imitation of structures and social relations, active learning, and learning by discovery. All these educational strategies are linked to prejudice, pre-comprehension and historical-effective consciousness, contributing to unveil the situation of the student in the world of life.

Finally, it is clear that the hermeneutics of the pedagogical question is yet to be analyzed, for with questioning the same as with the work of art is never fully understood.

\section{References}

[1] H-G. Gadamer, Education is self-education, Journal of Philosophy of Education, 35(4), 2001, 529-538.

[2] M.J. Hannafin, J.R. Hill, S.M. Land, and E. Lee, Student-centered, open learning environments: research, theory, and practice, in M.J. Spector, M.D. Merrill, J. Elen, and M.J. Bishop (Eds.), Handbook of research on educational communications and technology, $4^{\text {th }}$ ed, (New York: Springer, 2014) 641-652.

[3] M.A. Arbib, and M.B. Hesse, The construction of reality (Cambridge: Cambridge University Press, 1987).

[4] J.R. Searle, The construction of social reality (New York: The Free Press, 1995).

[5] J. Piaget, The child's conception of the world (London: Routledge \& Kegan Paul LTD, 1971).

[6] P. Hogan, Gadamer and the philosophy of education, in M.A. Peters (Ed.), Encyclopedia of educational philosophy and theory, (Singapore: Springer, 2015) 1-6.

[7] P. Freire, Pedagogy of freedom. Ethics, democracy, and civic courage, (Maryland: Rowman \& Littlefield Publishers, 2000).

[8] J. Piaget, To understand is to invent. The future of education, (New York: Grossman Publishers, 1973).

[9] J. Grondin, The hermeneutical circle, in N. Keane, and C. Lawn (Eds.), The Blackwell Companion to Hermeneutics, (Oxford: John Wiley \& Sons, Inc., 2016) 299-305.

[10] B. Bernstein, The structuring of pedagogic discourse (London: Routledge, 2003).

[11] R. Stevens, The questions as a measure of efficiency in instruction: a critical study of classroom practice (New York: Teachers College, Columbia University, 1912).

[12] A.P. Almeida, Can I ask a question? The importance of classroom questioning, Procedia: Social and Behavioral Sciences, 31, 2011, 634-638.

[13] A.F Fan, M. Levi, and A. Shammah, Classroom questioning as an invaluable teaching strategy in social studies, Global Advanced Research - Journal of Educational Research and Review, 3(1), 2014, 007-011.

[14] P. Albergaria-Almeida, Classroom questioning: teachers'perceptions and practices, Procedia: Social and Behavioral Sciences, 2, 2010, 305-309.

[15] A.G. Rillo, Hermenéutica de la pregunta pedagógica, Graffylia, 6(10), 2009, 184-192.

[16] A. Polanco Hernández, La pregunta pedagógica en el nivel inicial, Actualidades Investigativas en Educación, 4(2), 2004,1 -12.

[17] A.G. Rillo, M.L. Pimentel Ramírez, M.E. Arceo Guzmán, H. Ocaña Servín, L. García-Pérez, and D. Hernández-Monroy, Horizonte y estructura de la pregunta pedagógica, Actualidades Investigativas en Educación, 11(1), 2011, 1-18.

[18] H-G. Gadamer, Truth and method (London: Continuum Publishing Group, 2006).

[19] M. Heidegger, Interpretaciones fenomenológicas sobre Aristóteles: indicación de la situación hermenéutica [Informe Natorp] (España: Editorial Trotta, 2002).

[20] M. Heidegger, Being and time (Oxford, UK: Blackwell Publisher Ltd, 2001).

[21] H-G. Gadamer, El problema de la conciencia histórica, $2^{\mathrm{a}}$ ed. (Madrid: Editorial Tecnos, 2001).

[22] A.G. Rillo, M.L. Pimentel Ramírez, M.E. Arceo Guzmán, and J. Jaimes García, Hermeneutics pedagogical question: learning mediated by the practice of freedom from the perspective of Freire, Revista Internacional de Educación para la Justicia Social, 4(1), 2015, 35-53.

[23] M. Heidegger, ¿Qué es metafísica? (Madrid: Alianza Editorial, 2009).

[24] M. Heidegger, The question concerning technology and other essays (New York: Harper \& Row Publisher Inc, 1977).

[25] H-G. Gadamer, Verdad y método II (Salamanca: Ediciones Sígueme, 2002).

[26] W. Baker, Discovery method and teaching-research. In B. Czarnocha, W. Baker, O. Dias, and V. Prabhu (Eds.), The creative enterprise of mathematics teaching research, (Rotterdam: Sense Publisher, 2016) 245-252.

[27] J.M. Laguador, Cooperative learning approach in an outcomes-based environment, International Journal of Social Sciences, Arts and Humanities, 2(2), 2014, 46-55.

[28] A.R. Pope, and D.G. Lowe, Learning appearance models for object recognition, in J. Ponce, A. Zisserman, and M. Hebert (Eds.), Object representation in computer vision II, (Cambridge, UK: Springer-Verlag, 1996) 201-216. 
[29] R.A. Poldrack, and K. Foerde. Category learning and de memory systems debate, Neuroscience and Biobehavioral Reviews, 32, 2008, 197-205.

[30] P. Albergaria-Almeida, Questioning patterns and teaching strategies in secondary education, Procedia: Social and Behavioral Sciences, 2(2), 2010, 751-756.

[31] A. Bandura, Social learning theory (New Jersey: Prentice Hall, 1977).

[32] I.L. Götz, Heidegger and the art of teaching, Educational Theory, 33(1), 1983, 1-9.

[33] J. Schweppe, and R. Rummer, Attention, working memory, and long-term memory in multimedia learning: an integrated perspective based on process models of working memory, Educational Psychology Review, 26(2), 2014, 285-306.

[34] J. Schenck, and J. Cruickshank, Evolving Kolb: experiential education in the age of neuroscience, Journal of Experiential Education, 38(1), 2015, 73-95.

[35] D.M. Amodio, The neuroscience of prejudice and stereotyping, Nature Review Neuroscience, 15, $2014,670-682$.

[36] D. Wahidin, H.S. Muchtar, Y.L. Sulastri, and Z.W. Lestari, The implementation of active learning model for preparing pre-service teachers, GSTF Journal of Education, 4(2), 2017, 6-10. 